\section{PS-036 FACTORS AFFECTING COMPLIANCE WITH ENZYME REPLACEMENT THERAPY WITH IDURSULFASE IN CHILDREN WITH HUNTER SYNDROME: DATA FROM THE HUNTER OUTCOME SURVEY}

${ }^{1} \mathrm{M}$ Solano, ${ }^{2}$ Morin, ${ }^{3} \mathrm{C}$ Lampe. ${ }^{1}$ Department of Neuropediatrics, Fundación Cardioinfantil, Bogotá, Colombia; ${ }^{2}$ Rare Diseases, Shire, Eysins, Switzerland; ${ }^{3}$ Rare Disease Centre, Dr. Horst Schmidt Kliniken GmbH, Wiesbaden, Germany

10.1136/archdischild-2014-307384.331

Background and aims Manifestations of Hunter syndrome typically become apparent between 2 and 4 years of age; affected children may be treated with enzyme replacement therapy with idursulfase (Shire). This long-term treatment consists of weekly infusions generally administered over $3 \mathrm{~h}$. Patients may sometimes miss scheduled infusions. This analysis investigated the frequency of, and reasons for, missed idursulfase infusions and stopping treatment in children.

Methods This analysis used data from the Hunter Outcome Survey (HOS), a global, observational registry sponsored by Shire that collects real-world clinical information on the natural history of Hunter syndrome and the long-term effectiveness and safety of idursulfase.

Results As of January 2014, data on missed infusions and stopping treatment between HOS entry and last clinical evaluation recorded in HOS/treatment end (median, 35.4 months) were available for 483 children followed prospectively in HOS aged < 12 years at initiation of idursulfase treatment. The mean time from treatment start to last evaluation/treatment end was 47.2 months. In total, 1046 missed infusions were reported in 135/ 483 children (28.0\%). The most common reasons were illness (for $25.5 \%$ of missed infusions), holiday/vacation (10.0\%) and caregiver/family issues (7.9\%). At last evaluation, 31/483 patients $(6.4 \%)$ had stopped treatment; the most common reason (38.7\%) was the patient's/parents' decision.

Conclusions Analysis of HOS data reveals that a variety of factors affect treatment compliance; the most common reason for missing an infusion was illness. However, $72.0 \%$ of children receiving idursulfase did not miss a single infusion during this analysis period, and few children stopped treatment.

\section{PS-037 MATERNAL BARIATRIC SURGERY AFFECTS NEWBORN BODY COMPOSITION}

${ }^{1} \mathrm{E}$ Malchau Carlsen, ${ }^{1} \mathrm{~B}$ Kanijo Møller, ${ }^{2} \mathrm{KM}$ Renault, ${ }^{1} \mathrm{D}$ Cortes, ${ }^{3} \mathrm{KF}$ Michaelsen, ${ }^{4} \mathrm{O}$ Pryds. ${ }^{1}$ Department of Pediatrics, Hvidovre University Hospital University of Copenhagen, Hvidovre, Denmark; ${ }^{2}$ Department of Obstetrics and Gynaecology, Odense University Hospital University of Southern Denmark, Odense, Denmark; ${ }^{3}$ Department of Nutrition Excercise and Sports, University of Copenhagen, Hvidovre, Denmark; ${ }^{4}$ Department of Pediatrics, University of Copenhagen, Hvidovre, Denmark

\subsection{6/archdischild-2014-307384.332}

Background and aims Bariatric surgery (BS) is extensively used and one of few lasting ways to treat obesity. Women in child bearing age also undergo BS; BS-offspring has a lower mean birth weight and an increased risk of being small for gestational age compared to non-BS-offspring. The aim of our study was to assess how BS affects newborn body composition and if BS was associated with offspring aberrant fat deposition.

Methods Pregnant women who previous had Roux-en-Y-gastricbypass were included. Offspring anthropometric measurements were collected at birth and total and regional newborn body composition was assessed using dual-energy X-ray absorptiometry. The offspring of BS-mothers was compared to offspring of non-BS mothers. Aberrant fat deposition was defined as the percentage of total fat that was placed abdominally. Multiple linear regressions were used to assess the effect of BS.

Results We included 25 BS-offspring and 293 non-BS-offspring for comparison. There was no difference in maternal pre-pregnancy BMI between the groups $(\mathrm{p}=0.16)$. BS-offspring had lower birth weight $(-311 \mathrm{~g}, \mathrm{p}=0.002)$, lower fat percentage ($2.6 \%, \mathrm{p}=0.002)$, lower lean mass $(-260 \mathrm{~g}, \mathrm{p}<0.001)$ and $\mathrm{a}$ lower percentage of total fat placed abdominally $(-1.6 \%, \mathrm{p}=$ $0.024)$. The analyses were adjusted for pre-pregnancy obesity, maternal age, parity, gestational weight gain and newborn sex and gestational age.

Conclusion We observed significant differences in body composition between offspring of women with previous BS compared to those without surgery. The BS-offspring had lower birth weight, fat percentage and lean mass. There was no sign of aberrant fat deposition in BS-offspring.

\section{PS-038 FINAL HEIGHT IN PATIENTS WITH TYPE 1 DIABETES}

${ }^{1}$ AL Rodrigues, ${ }^{2}$ J Extreia, ${ }^{3} \mathrm{D}$ Amaral, ${ }^{3} \mathrm{R}$ Pina, ${ }^{3} \mathrm{C}$ Limbert, ${ }^{3} \mathrm{~L}$ Lopes. ${ }^{1}$ Serviço de Pediatria, Hospital Divino Espírito Santo, Ponta Delgada, Portugal; ${ }^{2}$ Serviço de Pediatria, Centro Hospitalar Barreiro Montijo EPE, Lisboa, Portugal; ${ }^{3}$ Unidade de Endocrinologia, Hospital Dona Estefânia Centro Hospitalar Lisboa Central, Lisboa, Portugal

\subsection{6/archdischild-2014-307384.333}

Background Type 1 Diabetes Mellitus (T1DM) is the most common metabolic disease in children. Growth parameters are important indicators of child's health.

Objective To evaluate final height of patients with T1DM correlating the metabolic control and disease duration with growth and puberty.

Subjects and methods Retrospective analysis of a cohort of adolescents, aged between 15 and 18 years, with T1DM, followed up to final height at a tertiary Hospital clinic. The variables collected were: age, sex, height at diagnosis, final height, parents' height, pubertal height gain, metabolic control during puberty (mean A1cHB). Statistical analysis was performed using SPSS ${ }^{2} 20$; results are presented as mean \pm SD.

Results Forty six adolescents were included [59\% male (M), $41 \%$ female $(\mathrm{F})]$. Mean age at diagnosis was $9.3 \pm 3.5$ years. Mean A1cHB was $8.15 \pm 1.4$. In 26 patients, T1DM was diagnosed before puberty; in these, the age at the onset of puberty was $10.8 \pm 1.5(\mathrm{M})$ and $9.2 \pm 0.6 \mathrm{SD}$ years $(\mathrm{F})$. Height SDS at diagnosis was $0.5 \pm 1.5(\mathrm{M})$ and $0.35 \pm 1.2(\mathrm{~F})$. Final height was $-0.2 \pm 1(\mathrm{M}) 0.08 \pm 0.9(\mathrm{~F})$. Target height was $-0.29 \pm 1.1$ (M) $-0.02 \pm 1(\mathrm{~F})$. Patients were significantly taller than their parents at diagnosis $(\mathrm{p}=0,03)$, and lost height during follow up to final height $(\mathrm{p}=0,004)$ yet final height was within target height $(p=0,3)$. There was no correlation between final height and metabolic control $(\mathrm{p}=0,9)$ or duration of diabetes $(\mathrm{p}=$ $0,4)$.

Conclusion In spite of a taller stature at diagnosis and variable metabolic control, final height was not compromised, arguing against growth compromise being a major hallmark of deficient metabolic control. 